\title{
Geographical Distribution of Biomphalaria pfeifferi snails in East Africa
}

\author{
Victor O. Magero1 ${ }^{2}$, Sammy Kisara², Christopher M. Wade ${ }^{1}$ \\ ${ }^{1}$ School of Life Sciences, University of Nottingham, Nottingham NG7 2RD \\ 2Institute of Primate Research, P.O. Box 24481 Karen 00502 \\ Nairobi, Kenya
}

\begin{abstract}
There is limited information on the distribution of B. pfeifferi, an important snail intermediate host of schistosomiasis, in East Africa. This study assessed the incidence and geographical distribution of $B$. pfeifferi snails in Kenya, Uganda and Tanzania. Maximum Entropy modeling was used to predict the potential distribution of $B$. pfeifferi snails, in line with habitat suitability. Malacological surveys were then conducted guided by MaxEnt predictions and information obtained from previous research papers. The surveys were conducted at a total of 156 sites including streams, rivers, lake shores, dams and irrigation canals over a 3 year period (2018 to 2020). Geographical coordinates, ecological and physicochemical information was recorded for the sites visited. Snails were identified morphologically, based on shell characters using established identification keys. B. pfeifferi snails were found at $23.07 \%(36 / 156)$ of the sites sampled. Streams proved to be the habitats most preferred by $B$. pfeifferi snails ( $50 \%$ of all of the sites where the snails were found were streams), followed by rivers $(20.6 \%)$, irrigation canals $(8.8 \%)$, lake shores $(8.8 \%)$, springs $(5.9 \%)$, and dams (5.9\%) with snail abundance increasing with increase in temperature and decrease in water depth. B. pfeifferi was found in the Lake Victoria basin, Mwea Irrigation Scheme and Eastern Province of Kenya, the Lake Albert region, Lango region, Soroti district, Lower Moshi irrigation scheme, Babati district, Iringa region, Tabora region and Kigoma region. Information on the distribution of $B$. pfeifferi in East Africa will aid in developing prevention and control strategies for schistosomiasis.
\end{abstract}

Keywords: Intestinal schistosomiasis, Biomphalaria pfeifferi, East Africa 


\section{AUTHOR SUMMARY}

Few studies have been conducted on the distribution of $B$. pfeifferi snails in East Africa with previous studies mostly isolated projects restricted to single divisions, districts and regions. Knowledge on the distribution of snail intermediate hosts can be helpful in establishing schistosomiasis transmission surveillance systems for detecting emerging and prevailing incidences of schistosomiasis. We undertook malacological surveys of freshwater sites across Kenya, Uganda and Tanzania. A total of 156 sites were sampled and B. pfeifferi snails were found at 36 of the sites. Streams yielded the highest number of snails, in comparison to the other habitats that were sampled. Temperature and water depth were established to be statistically significant ecological and physicochemical factors that influence incidences and abundance of the snails. This study provides important information on the distribution of an important snail intermediate host in East Africa and the knowledge obtained herein can be helpful in establishing appropriate schistosomiasis control initiatives.

\section{INTRODUCTION}

Schistosomiasis is a neglected tropical disease caused by flatworms of the genus Schistosoma. The disease is ranked second to malaria in terms of tropical diseases of public health importance (Colley et al., 2014). It is estimated that about 1 billion people globally are at risk of being infected with the disease and about 250 million people are currently infected (Gryseels, 2012). 200,000 deaths are attributable to the disease annually (Colley et al., 2014). The disease has debilitating effects on individuals because it renders them unproductive due to malaise and disability. In particular, the disease is catastrophic to school aged children because it impedes them from attending school due to physical incapacity associated with the disease, thus jeopardising their chances of having a brighter future. There are two forms of schistosomiasis, urogenital schistosomiasis caused by $S$. haematobium and intestinal schistosomiasis caused by S. mansoni and S. japonicum (Colley et al., 2014). Other human Schistosoma parasites albeit not significant from a public health perspective include $S$. intercalatum, S. mekongi and S. guineensis (Gryseels, 2012). Schistosoma mansoni is responsible for most cases of human intestinal schistosomiasis in Africa and the Americas; it is solely responsible for 83 million out of an estimated total 250 million global schistosome infections (Morgan et al., 2005).

Snail intermediate hosts are important because they support the transformation of Schistosoma parasites into infective stages (Zeng et al., 2017). Snail intermediate hosts for $S$. mansoni belong to the genus Biomphalaria. In the Americas, intermediate hosts for S. mansoni include B. glabrata, B. tenagophila and B. straminea (Habib et al., 2021). Fossil records assert that African Biomphalaria species originated from B. glabrata, during the Plio- Pleistocene period when $B$. glabrata invaded the African continent (Campbell et al., 2000). In East Africa, there are several species of the genus Biomphalaria including $B$. 
sudanica, B. choanomphala, B. smithi, B. stanleyi, B. angulosa and B. pfeifferi (Standley \& Vounatsou, 2012).

B. pfeifferi, B. sudanica and B. stanleyi have been identified from Lake Albert (Rowel et al., 2015) while B. sudanica and $B$. choanomphala have been identified from Lake Victoria (Standley et al., 2011; Standley et al., 2014). B. sudanica and $B$. smithi have been found from Lake Edward (Mandahl, 1957). Biomphalaria snails, although not identified to the species level have been collected from Mount Elgon, Rwenzori Mountains and Fort Portal crater lakes (Stanton et al., 2017). B. sudanica snails have also been found in Northern and North Eastern parts of Uganda (Habib et al., 2021).

B. pfeifferi snails have been found in Uganda at Lwampanga, Masindi Port, Muzizi, Ngamilajojo, Butiaba and Ntoroko (Lake Albert) (Jorgensen et al., 2007). B. pfeifferi snails have also been found in Northern and North Eastern parts of Uganda (Habib et al., 2021). In Kenya, B. pfeifferi snails have been found at Muthamo seepage, Matingani seepage, Mbondoni dam, Kangonde dam, Mwea East, Mwea West, Onsando dam, Grogan Canal, Kamayoga stream, Asawo stream, Kwahoma stream and Martin's drain (Bandoni et al., 1990). Malacological surveys by Opisa et al. (2011), at informal settlings of Kisumu City, Kenya identified two Biomphalaria species, B. sudanica and B. pfeifferi, revealing a risk of schistosomiasis transmission at this location. $B$. pfeifferi snails were also found in Kenya, at the Mwea irrigation scheme, Asawo stream and Mukou stream by Mutuku et al. (2020). A study by Buddenborg et al. (2017) identified and collected $B$. pfeifferi from Kasabong stream, Asembo village (Western Kenya). B. pfeifferi snails have also been reported from Kenya at Kibwezi (Jorgensen et al., 2007) as well as Chebunyo dam (Bomet County) and Churo pond (Kirinyaga County) (Bandoni et al., 2000). B. pfeifferi snails have also been collected from Asawo River and Kasabong stream, in Western Kenya (Lu et al., 2016). In Tanzania, B. pfeifferi snails have been found at the southern part of the country, around Gombe National Park (Bakuza et al., 2017) and have been identified and collected in the Northern part of Tanzania (in Babati district and Lower Moshi irrigation scheme) by Lydig (2009) and Kisanga (1991) respectively. B. pfeifferi has also been found in Kilombero district, Tanzania (Utzinger \& Tanner, 2000). The previous studies on the distribution of B. pfeifferi snails in East Africa (Kenya, Uganda and Tanzania) have not covered expansive geographical areas. The greater the abundance of snail intermediate hosts in any geographical location, the higher the probability that human beings will come in contact with Schistosoma parasites and be infected (Bakuza et al., 2017).

Intestinal schistosomiasis has been reported to be endemic in several localities in East Africa (Aula et al., 2021). However, there has been little information on the role that $B$. pfeifferi plays in transmission of schistosomiasis in those localities yet $B$. pfeifferi is arguably the most important snail intermediate host in Africa because of its widespread distribution and high degree of susceptibility to S. mansoni infections (Buddenborg et al., 2017). An increase in schistosome 
infections in snail intermediate hosts, leads to contamination of water bodies with active cercariae thus meaning that human beings become at more risk of being infected with the parasites. Some of the localities and regions where intestinal schistosomiasis has been reported to be endemic, with little to no reports on snail intermediate hosts include Lango region (Adriko et al., 2018), West Nile region (Imran, 2014), Soroti district and Kibimba irrigation scheme (Ejotre et al., 2014). There is a therefore a need to extensively establish the distribution of $B$. pfeifferi snails in East Africa, because of limited information about their distribution and their significance as an important intermediate host in the transmission of schistosomiasis. Understanding distribution of $B$. pfeifferi in East Africa would influence decision making as far as development of effective and integrated strategies to combat transmission of human intestinal schistosomiasis is concerned.

This study therefore aimed to assess the incidence of $B$. pfeifferi snails and their current geographical distribution in East Africa as well as determine which types and physicochemical and ecological parameters are associated with the abundance of the snails.

\section{MATERIALS AND METHODS}

\section{Ecological modeling and evaluation}

Ecological modeling was done using MaxEnt (Phillips et al., 2006), a machine learning algorithm that is used to predict the potential distribution of species, based on the principle of maximum entropy in a situation where there is incomplete information about the distribution of a given species and the environmental factors that promote its habitation. To conduct maximum entropy species distribution modelling, occurrence points-data (sites where B. pfeifferi have been found previously) and environmental layers (bioclimatic factors and environmental factors that affect the distribution of species) are required.

Occurrence records for $B$. pfeifferi snails were obtained from the Global Biodiversity Information Facility database (GBIF (https://www.gbif.org/). A total of 56 occurrence records were retrieved from GBIF. Bioclimatic variables were obtained from WorldClim.org and soil type and land cover variables obtained from respective databases. Soil type variables were derived from https://www.isric.org/explore/soil-geographic-databases and land cover variables were derived from http://2016africalandcover20m.esrin.esa.int/download.php 


\section{Malacological surveys}

MaxEnt predictions, past knowledge on the distribution of $B$. pfeifferi snails and areas where intestinal schistosomiasis has been reported to be endemic in East Africa guided where we undertook our malacological surveys. Additionally, we visited water bodies in regions that have previously been reported as having cases of intestinal schistosomiasis, on the basis that there must be snail intermediate hosts that transmit the disease in those localities.

Malacological surveys were conducted from January 2018 to March 2018, December 2018 to February 2019 and January 2020 to March 2020, from 156 sites, across East Africa (Figure 1). These included 75 sites in Kenya, 26 sites in Uganda and 55 sites in Tanzania. The surveys involved searching edges of streams, river banks, irrigation canals, lake shores, springs and dams for snails, for around 30 minutes, usually covering a distance of approximately $20 \mathrm{~m}$ and an area of around $7 \mathrm{~m}^{2}$ per site. Snails that were found were collected using a handheld scoop. Geographical coordinates for each site were recorded using a handheld Garmin eTrex 10 GPS (Kansas City, USA). The snails were then sorted by turning them upside down on the wire mesh of the collection scoop to check their shell characters. Identification keys developed by Kristensen, (1987) were used to identify $B$. pfeifferi snails based on their morphological characters including the general shape of the shell, the shape of the whorls, the number of coils and the shape of the aperture. $B$. pfeifferi shells are approximately $15 \mathrm{~mm}$ wide, typically dark black in colour, flat, sinistral and left-coiled (Kristensen, 1987). The snails were transferred to a collection jar then washed and placed in Falcon tubes while in the field. To preserve the snails, absolute ethanol was added to the lab bottles containing the snails to a volume double that occupied by the snails. Ethanol in the lab bottles was changed two to three times, to ensure that ethanol penetrated into the snails' tissues. After completion of fieldwork, the lab bottles containing the snails were stored in a $-20^{\circ} \mathrm{C}$ freezer. 

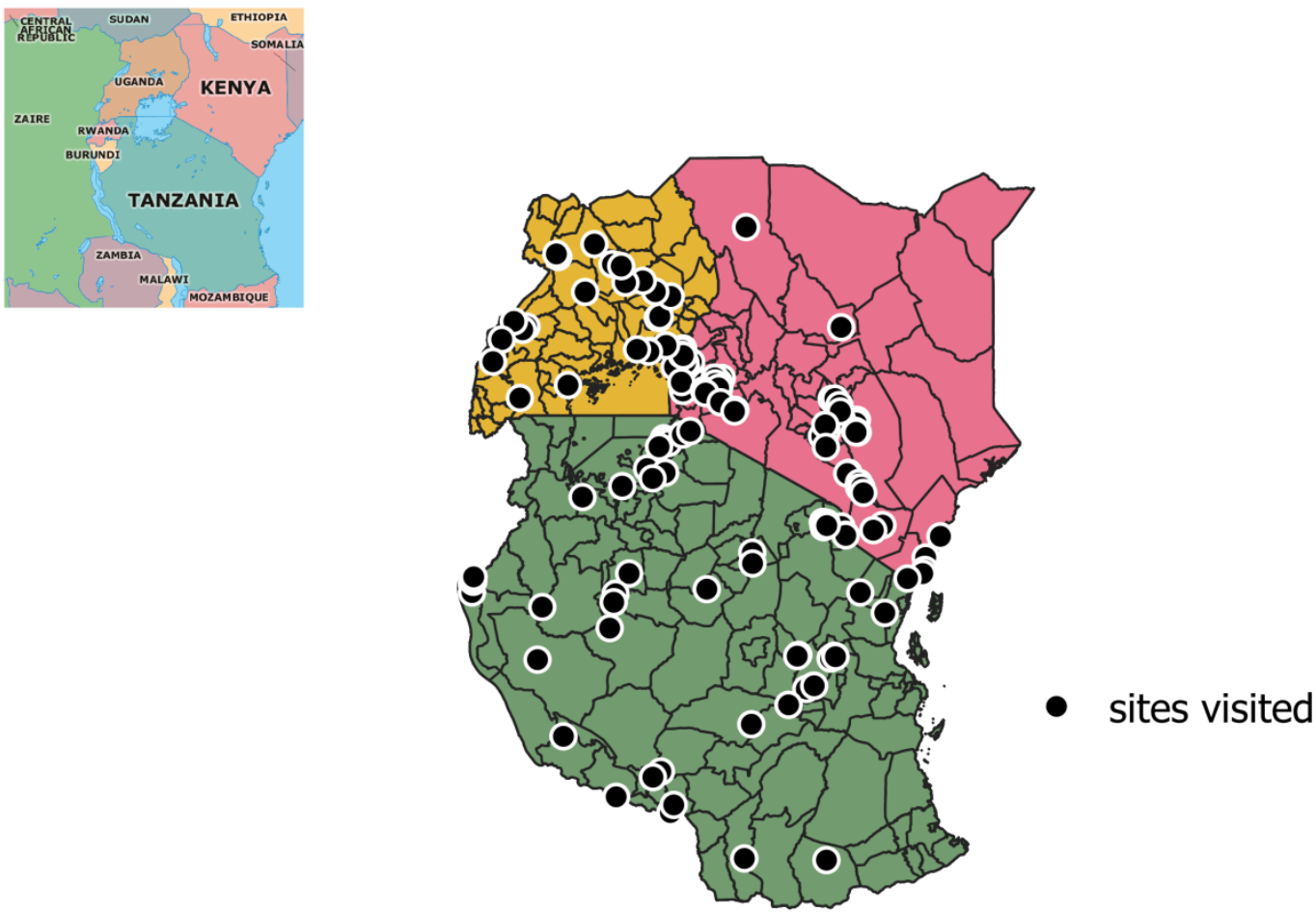

Figure 1: A map of East Africa showing sites that were visited for purposes of malacological surveys

\section{Ecological and physicochemical parameters}

Ecological and physicochemical parameters associated with snail abundance were recorded. These parameters included vegetation type, water temperature and $\mathrm{Ph}$. Water temperature and $\mathrm{Ph}$ were recorded using a portable water metre (Hanna Instruments, Møllevænget, Sweden).

Water depth was also recorded using a 1 metre ruler. Furthermore, water velocity was recorded using a flowmeter. Additionally, we noted and recorded the soil type for each site.

\section{Data processing and analysis}

Maps showing sites that were visited, sites where $B$. pfeifferi snails were found in relation to snail abundance were created by QGIS version 3.12.3. The name of the site, coordinates, availability of snails, snail numbers, ecological and physicochemical parameters for each site were recorded in Microsoft Excel.

For the purpose of determining ecological and physicochemical factors associated with snail abundance, the Gaussian log function was used. In this function, $B$. pfeifferi snail abundance was used as an outcome while independent variables were the physicochemical and ecological parameters. Negative Binomial 
bioRxiv preprint doi: https://doi.org/10.1101/2021.11.04.467236; this version posted November 4, 2021. The copyright holder for this preprint (which was not certified by peer review) is the author/funder, who has granted bioRxiv a license to display the preprint in perpetuity. It is made available under aCC-BY 4.0 International license.

Generalised linear mixed models (GLMMs) were fitted in R Version 4.1.0 using the package 'glmmTMB' to test association between snail abundance and parameters.

\section{RESULTS}

4.1 Potential distribution of $B$. pfeifferi snails determined by MaxEnt

B. pfeifferi snails are predicted to be widely distributed in East Africa based on MaxEnt analysis (Figure 2). Locations where there is a high probability that $B$. pfeifferi snails will be found are shown in red while the blue colour shows locations where there is little probability that the habitat is suitable for the habitation of $B$. pfeifferi snails. The figure suggests that $B$. pfeifferi is endemic in East Africa.
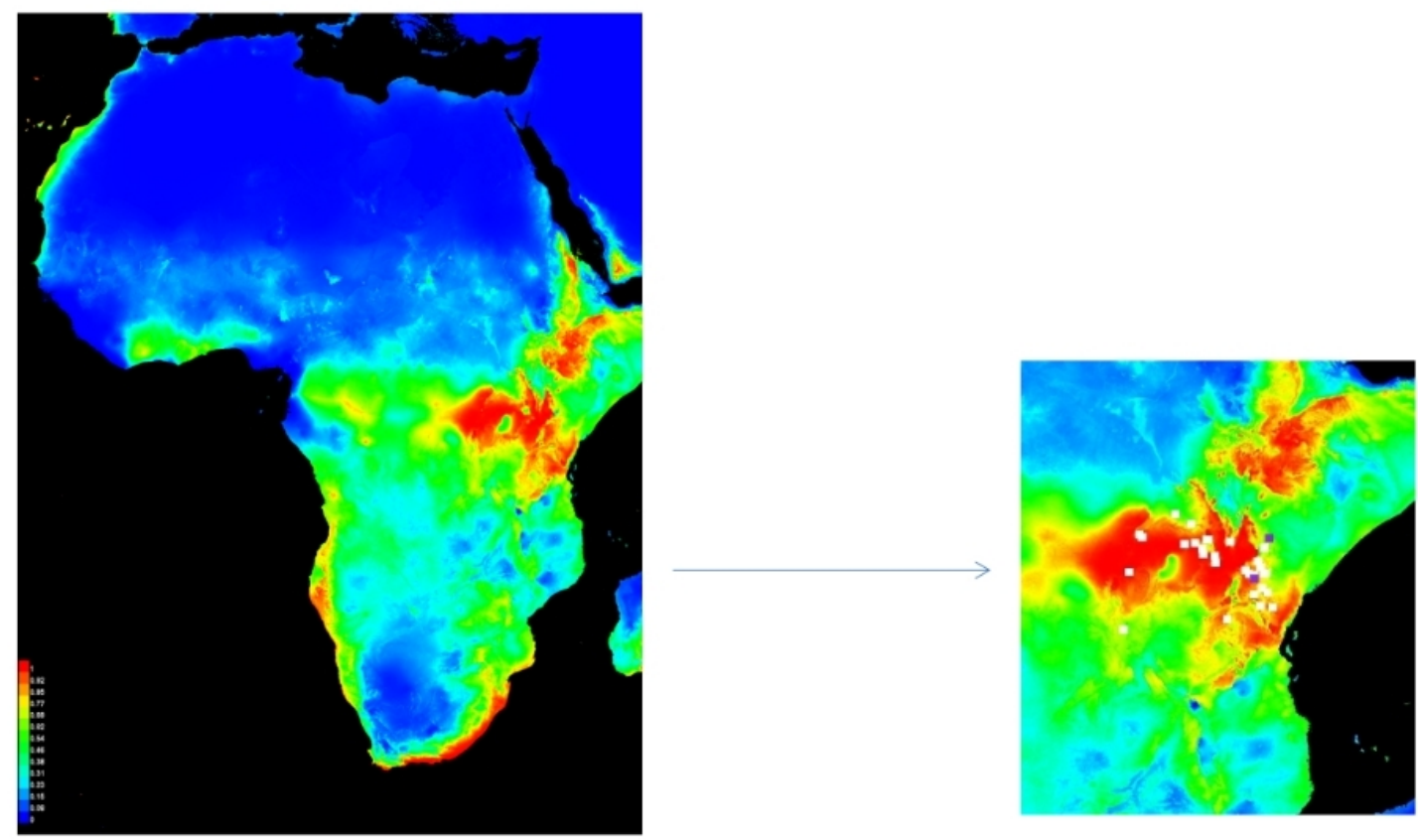

Figure 2: Potential distribution of B. pfeifferi snails in Africa and East Africa, courtesy of MaxEnt

\subsection{Presence and incidence of $B$. pfeifferi snails}

A total of 156 sites were visited across East Africa and B. pfeifferi snails were found at 36 of these sites (Figure 3). Melanoides tuberculata was found at 7 of the 156 sites visited and even though the habitat of the sites where $M$. tuberculata were found were suitable for the habitation of $B$. pfeifferi, $B$. pfeifferi was only found together with $M$. tuberculata at one site (Ntoroko beach, Lake Albert). 

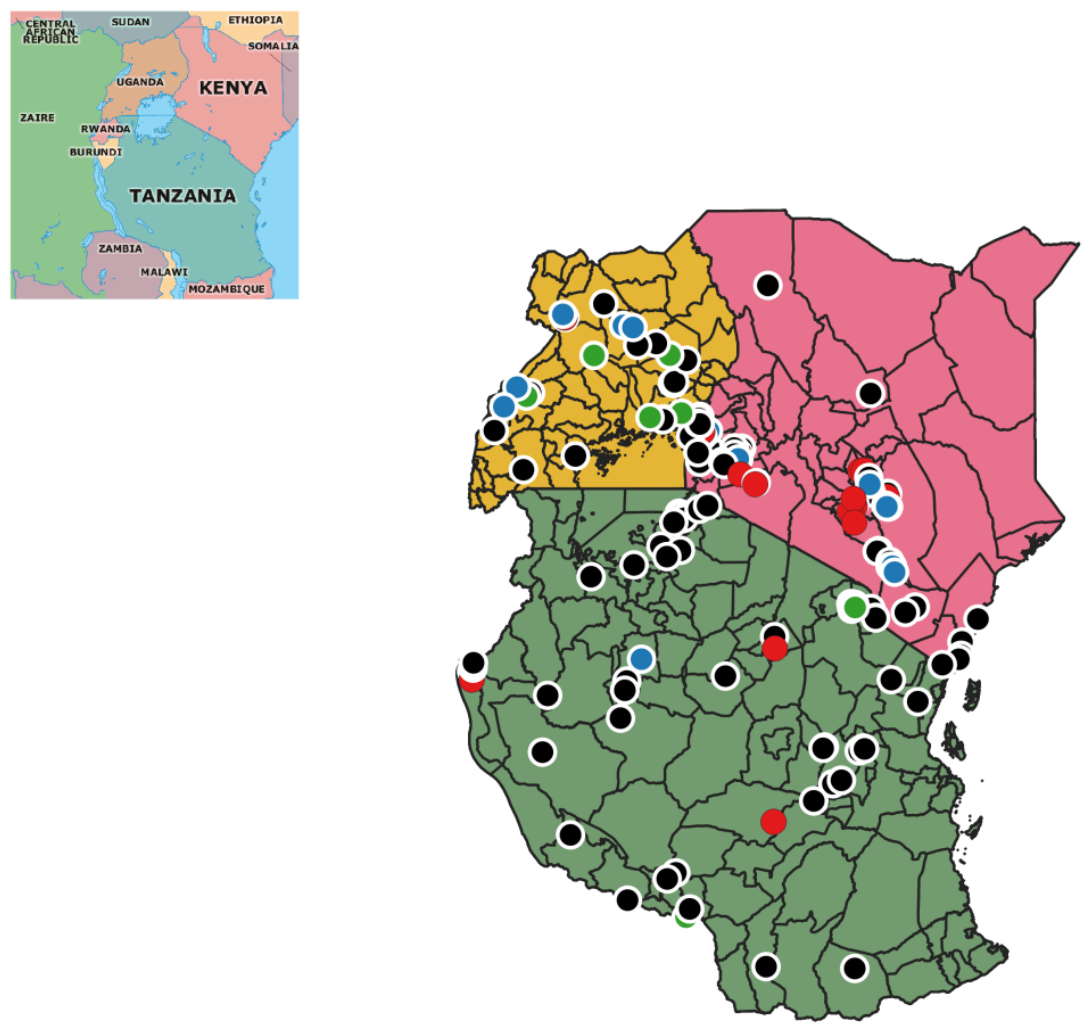

legend

- no snails

- $\mathrm{n}<10$

- $\mathrm{n}<20$

$\mathrm{n}>20$

Figure 3: Incidences of B. pfeifferi snails in East Africa, in regard to their abundance

B. pfeifferi snails were found in rivers, streams, lakes shores, irrigation canals, springs and dams. Most of the sites where $B$. pfeifferi were found were streams $(50 \%)$, followed by rivers $(20.6 \%)$, irrigation canals $(8.8 \%)$, lake shores $(8.8 \%)$, springs $(5.9 \%)$, and dams (5.9\%).

Supplementary Table 1 shows all sites that were visited for the purposes of conducting malacological surveys.

\subsection{Ecological and physicochemical parameters}

Data on vegetation availability, type of vegetation, water temperature, soil type, $\mathrm{Ph}$, Water depth and water velocity was recorded for each site (Supplementary Table 2). Water temperature at the sites ranged from $19.1^{\circ} \mathrm{C}-27.4^{\circ} \mathrm{C}$ and the median (interquartile range) water temperature was $23.6^{\circ} \mathrm{C}\left(21.18^{\circ} \mathrm{C}-25.23^{\circ} \mathrm{C}\right)$. The water-depth of the sites ranged from $19.3 \mathrm{~cm}-41.3 \mathrm{~cm}$ and the median (interquartile range) water depth was $27.45 \mathrm{~cm}(23.1 \mathrm{~cm}-32.4 \mathrm{~cm})$. Based on negative binomial regression in glmmTMB, only temperature and water depth had a statistically significant positive relationship with the abundance of $B$. pfeifferi snails ( $\mathrm{p}$-values of 0.00184 and 0.0187 respectively). The other variables (vegetation, $\mathrm{pH}$, soil type and presence of competitor snails) did not 
show any statistically significant relationship with the abundance of $B$. pfeifferi snails (Table 1 ).

\begin{tabular}{|c|c|c|c|c|}
\hline Variables & Estimate & Std. Error & $\begin{array}{l}\text { Confidence } \\
\text { Interval }\end{array}$ & p-value \\
\hline Intercept & -7.11562 & 3.93026 & $\begin{array}{l}-14.81878984 \\
-0.5875451\end{array}$ & 0.07022 \\
\hline Vegetation & 1.82671 & 1.48377 & $\begin{array}{l}-1.08143734- \\
4.7348507\end{array}$ & 0.21828 \\
\hline Temp & 0.2508 & 0.08051 & $\begin{array}{l}0.09300019- \\
0.4085942\end{array}$ & $0.00184 * *$ \\
\hline $\mathrm{Ph}$ & 0.33459 & 0.43332 & $\begin{array}{l}-0.51471196- \\
1.1838902\end{array}$ & 0.44003 \\
\hline Water-depth & -0.07316 & 0.03113 & $\begin{array}{l}-1.341682 \mathrm{e}- \\
01-- \\
1.215556 \mathrm{e}-02\end{array}$ & $0.0187 *$ \\
\hline Soil type & -0.51384 & 0.31513 & $\begin{array}{l}- \\
1.131483 \mathrm{e}+00 \\
-1.038082 \mathrm{e}- \\
01\end{array}$ & 0.1030 \\
\hline $\begin{array}{l}\text { Competitor } \\
\text { snails }\end{array}$ & -23.64088 & 9561.62528 & $\begin{array}{l}-\overline{1.876408 e+04} \\
- \\
1.871680 e+04\end{array}$ & 0.9980 \\
\hline Water velocity & -0.01207 & 0.02130 & $\begin{array}{l}-5.381777 e- \\
02- \\
2.967123 e-02\end{array}$ & 0.5708 \\
\hline
\end{tabular}

*Statistical significance at $p<0.05$

Table 1: The correlation between snail abundance ecological and physicochemical parameters courtesy of glmmTMB in $R$

\subsection{DISCUSSION}

This study presents an extensive survey of $B$. pfeifferi snails in East Africa with sampling undertaken from 156 sites across Kenya, Uganda and Tanzania. It was established that $B$. pfeifferi snails are widely distributed across East Africa and that the snails have a preference for streams ( $50 \%$ of all of the sites where the snails were found were streams), followed by rivers at $20.6 \%$. This suggests that streams are the most ideal aquatic habitats for $B$. pfeifferi. B. pfeifferi snails were also found in lake habitats, with $B$. pfeifferi collected from Lake Albert, Lake Babati and Lake Tanganyika. The snails were also found in irrigation schemes, dams and springs. In Kenya, the snails were found around the Lake Victoria basin (Kisumu County, Busia County, Siaya County, Kisii County, Homa Bay County and Nyamira County); at Mwea irrigation scheme, Machakos County, Kitui County and Makueni County. In Uganda, the snails were found around the Lake Victoria basin, at Lake Albert, Masindi Port, Kyenjojo, Pakwach, Kole district and Soroti district. In Tanzania, the snails were found in Babati district, Kilimanjaro region, Iringa region, Tabora region and Kigoma region. 
Transmission of schistosomiasis is not possible in areas where there is absence of snail intermediate hosts and therefore, understanding the distribution of the snails has a role to play in prevention and control of the disease. This knowledge on the distribution of $B$. pfeifferi snails in East Africa can support surveillance responses in terms of detecting new transmission foci and potential schistosomiasis hotspots.

Ecological and physicochemical parameters have an influence on the distribution of $B$. pfeifferi snails in East Africa. Temperature was established to be a crucial factor as far as geographical distribution of the snails is concerned with water temperature established to be the most significant parameter that influences the distribution of the snails ( $p$-value $=0.00184)$. Temperature as a climatic factor is very important for the survival of Biomphalaria snails (Yang et al., 2018). Sites where less than 20 snails were found had a temperature range of between $19.1^{\circ} \mathrm{C}$ to $21.3^{\circ} \mathrm{C}$. On the other hand, sites where more than 20 snails were found had a temperature range of between $23.2^{\circ} \mathrm{C}$ to $26.1^{\circ} \mathrm{C}$. This suggests that temperature has a role to play in the abundance of $B$. pfeifferi snails in aquatic habitats. According to Yang et al. (2018), ideal temperature is important for the fecundity of snail intermediate hosts. Sturrock (1965) states that Biomphalaria snails are active at temperatures of between $18^{\circ} \mathrm{C}$ and $32^{\circ} \mathrm{C}$ while reproduction and survival of the snails is optimum at a temperature range of between $20^{\circ} \mathrm{C}$ and $26^{\circ} \mathrm{C}$. Optimum temperature is also important as far as the production of cercariae is concerned (Yang et al., 2018). Previous studies suggest that Biomphalaria snails are not as temperature tolerant as Bulinus snails and high temperatures discourage their habitation (Sturrock, 1965). Our findings reveal that sites that had temperatures of above $27^{\circ} \mathrm{C}$ had low snail densities compared to sites that had temperatures of around $25^{\circ} \mathrm{C}$. This explains why Bulinus snails have previously been found in arid and semi-arid areas whereas Biomphalaria snails are rarely found in such environmental conditions (Sturrock, 1965). Our findings corroborate with a study by Ofulla et al. (2013) which avers that $B$. pfeifferi snails are less tolerant of temperatures above $27^{\circ} \mathrm{C}$. Habib et al. (2021) asserts that temperature is an important factor for Biomphalaria snails' reproduction and survival and that temperature changes may alter the breeding, survival and distribution of the snails. A positive correlation between water temperature and $B$. sudanica has also been reported previously (Kazibwe et al., 2006). Temperatures higher than optimal values negatively interfere with egg production and development of reproductive organs (Habib et al., 2021).

Water-depth was also established to be of statistical significance in relation to $B$. pfeifferi snail abundance ( $p$-value $=0.0187$ ). Snail abundance decreased with increase in water depth. High snail densities were found in Kakulutuine stream, a shallow stream less than $0.3 \mathrm{~m}$ deep and the high snail density could be attributed to the shallowness of the stream. A study by Hamman et al. (2000) asserts that water depth is an important factor as far as distribution of snail intermediate hosts is concerned and that there is a correlation between shallowness of a water body and the abundance of the intermediate hosts. In 
addition, Ofulla et al., (2013) showed a negative correlation between snail density and water depth in aquatic habitats of Lake Victoria basin. It is worth pointing out that water is an important factor for the survival of snails but too much of it decimates snail populations (Manyangadze et al., 2021).

Presence of vegetation in aquatic habitats has a role to play in the distribution of freshwater snails (Lodge et al., 1987). Although we did not find statistical significance between vegetation and snail abundance ( $p$-value $=0.21828$ ), previous studies have reported that aquatic plants play an important role in the distribution and habitation of snails because they provide the necessary conditions for feeding, oviposition, breeding as well as shelter (Gallardo et al., 2017). The types of vegetation that were found in close proximity to $B$. pfeifferi snails included submerged vegetation, floating vegetation, phytoplankton, Nymphaea caerulea, Nasturtium officinale, Enhydra fluctuans, Colocasia esculenta, algae and Maranta arundinacea. Enhydra fluctuans has been associated with $B$. sudanica snail abundance along the shores of Lake Victoria in Mbita, Kenya (Odero et al., 2019). Shallow vegetation has also been associated with the abundance of $B$. sudanica snails in Mwanza region, on the shores of Lake Victoria, in Tanzania (Gouvras et al., 2017). According to Kloos et al. (2014), presence of Nasturtium officinale is directly linked to the abundance of B. glabrata snails. On the other hand, Nymphaea caerulea has been associated with the abundance of $B$. pfeifferi snails (Ofulla et al., 2013). A study by Thomas (1987) suggests that Biomphalaria snails can utilise submerged macrophytes as a nutritional source.

Soil type has an influence on snail abundance (Ofulla et al., 2013). Despite the fact that we did not find statistical significance between soil type and snail abundance ( $p$-value $=0.21828$ ), we noticed that muddy soils promoted the habitation of the snails. Muddy soils have been noted to be important as far as survival of Biomphalaria snails is concerned because they protect snails from desiccation during hot and dry seasons (Lydig et al., 2009). Sandy soil is not conducive for the habitation of $B$. pfeifferi snails and low snail abundance was found in water bodies rich in sandy soil. An example is Tulimuimbu stream, in Eastern province, Kenya that had lower snail abundance. Lydig et al. (2009) posits that rich black cotton soils that are rich in organic matter are favourable for the habitation of Biomphalaria snails. According to Ofulla et al. (2013), the substratum in any given habitat has a role to play in the availability of snails and clay soil and silt constitute very important substrata favourable for the survival of Biomphalaria snails. Therefore, absence of Biomphalaria snails in a given location could be due to the lack of the right substrata.

Water velocity has been established to have an influence on the distribution and abundance of freshwater snails (Rabone et al., 2019; Ntonifor \& Ajayi, 2007; ElDeeb et al., 2017). In spite of the fact that we did not find statistical significance between water velocity and snail abundance $(p$-value $=0.5708)$, it has been reported previously that Biomphalaria snails are not found in sites with water 
velocities greater than $30 \mathrm{~cm} / \mathrm{s}$ (Appleton, 1978). We observed that water velocity higher than $30 \mathrm{~cm} / \mathrm{s}$ negatively correlated with $B$. pfeifferi snail abundance. Water velocities higher than $30 \mathrm{~cm} / \mathrm{s}$ are a limiting factor as far as snail abundance is concerned. According to Appleton (1978), water velocities have a tendency to sweep Biomphalaria snails from one location to another, mostly during the rainy season. Floods are a bottleneck that has been confirmed to have a direct impact on the availability and distribution of Biomphalaria snails (Habib et al., 2021).

Competitor snails of Biomphalaria snails are regarded as biotic factors that affect the distribution of $B$. pfeifferi snails (Pointier et al., 1993). While we did not find statistical significance between the presence of Melanoides tuberculata (a competitor snail) and the abundance of B. pfeifferi ( $p$-value $=0.9980)$, previous studies affirm that $M$. tuberculata, a highly invasive snail species is very effective in displacing Biomphalaria snails (Geshaw et al., 2008 and Pointier, 1993). B. pfeifferi snails were absent in most of the sites where we found $M$. tuberculata in our study except at Ntoroko beach (Lake Albert). Competitor snails of $B$. pfeifferi snails in East Africa would therefore seem to have an effect on the distribution of $B$. pfeifferi in the region albeit not significant in our glmmTB analyses.

Competitor snails have been used in schistosomiasis control by eliminating the snail intermediate host thus interrupting the transmission of Schistosoma parasites. Natural enemies of Biomphalaria snails such as Marisa snail that competes with Biomphalaria snails for food and also eats their eggs has been used to control snail populations of Biomphalaria snails. Marisa species are widely distributed in South America, Africa, Central America and the Caribbean (Muller, 1975). Introduction of Marisa snails in new habitats occupied by Biomphalaria snails has played a major role in decimating Biomphalaria snail populations (Muller, 1975).

\section{CONCLUSION}

This study showed that $B$. pfeifferi is widely distributed in East Africa and its distribution is influenced by ecological and physicochemical factors. Temperature and water depth were established as the most important factors that influence the geographical distribution of the snails. Other factors that influence the distribution of the snail intermediate hosts in East Africa, albeit not statistically significant include vegetation, $\mathrm{pH}$, water-velocity, soil type and presence of competitor snails. This study provides updated information on the distribution of $B$. pfeifferi snails in East Africa and contributes towards the body of knowledge on schistosomiasis and the snail intermediate hosts. Although B. pfeifferi snail sampling was conducted extensively in East Africa, further sampling should be conducted in future because of the seasonality of the water bodies that are inhabited by the snails and the ravages caused by floods and droughts to those very habitats. 


\section{REFERENCES}

Adriko, M., Faust, C., Carruthers, L., Moses, A., Tukahebwa, E., \& Lamberton, P. (2018). Low Praziquantel Treatment Coverage for Schistosoma mansoni in Mayuge District, Uganda, Due to the Absence of Treatment Opportunities, Rather Than Systematic Non-Compliance. Tropical Medicine and Infectious Disease, 3, 4, 111.

Adriko, M., Tinkitina, B., Tukahebw, E. M., Standley, C. J., Stothard, J. R., \& Kabatereine, N. B. (2018). The epidemiology of schistosomiasis in Lango region Uganda 60 years after Schwetz 1951: Can schistosomiasis be eliminated through mass drug administration without other supportive control measures? Acta Tropica, 185, 412-418.

Appleton, C. C. (1978). Review of literature on abiotic factors influencing the distribution and life cycles of Bilharziasis intermediate host snails. Malacology 11,1-25.

Aula, O. P., McManus, D. P., Jones, M. K., \& Gordon, C. A. (2021). Schistosomiasis with a Focus on Africa. Tropical Medicine and Infectious Disease, 6, 3.

Bakuza, J. S., Gillespie, R., Nkwengulila, G., Adam, A., Kilbride, E., \& Mable, B. K. (2017). Assessing S. mansoni prevalence in Biomphalaria snails in the Gombe ecosystem of western Tanzania: the importance of DNA sequence data for clarifying species identification. Parasites \& Vectors, 10, 1.

Bandoni, S. M., Mulvey, M., \& Loker, E. S. (2000). Population structure and taxonomic discrimination among three species of Biomphalaria Preston, 1910 (Gastropoda: Planorbidae) from Kenya. Zoological Journal of the Linnean Society, 129, 3, 387-401.

Bandoni, S., Mulvey, M., Koech, D., \& Loker, Eric. (1990). Genetic structure of Kenyan populations of Biomphalaria pfeifferi (Gastropoda: Planorbidae). Journal of Molluscan Studies, 56, 3, 383-391.

Buddenborg, S. K., Bu, L., Zhang, S.-M., Loker, E. S., Schilkey, F. D., \& Mkoji, G. M. (2017). Transcriptomic responses of Biomphalaria pfeifferi to Schistosoma mansoni: Investigation of a neglected African snail that supports more S. mansoni transmission than any other snail species. Plos Neglected Tropical Diseases, 11, 10.

Campbell, G., Jones, C. S., Lockyer, A. E., Hughes, S., Brown, D., Noble, L. R., \& Rollinson, D. (2000). Molecular evidence supports an African affinity of the Neotropical freshwater gastropod, Biomphalaria glabrata, Say 1818, an intermediate host for Schistosoma mansoni. Proceedings of the Royal Society of London. Series B: Biological Sciences, 267, 1460, 2351-2358. 
Colley, D. G., Bustinduy, A. L., Secor, W. E., \& King, C. H. (2014). Human schistosomiasis. The Lancet, 383, 9936, 2253-2264.

El-Deeb. F. A. A., El-Shenawy, N. S., Soliman, M. F. M., \& Mansour, S. A. (2017). Freshwater Snail Distribution Related to Physicochemical Parameters and Aquatic Macrophytes in Giza and Kafr El-Shiekh Governorates, Egypt. International Journal of Veterinary Science and Research, 3, 1, 8-13.

Ejotre, I., Nachuha, S., \& Mwima, P. (2014). Assessment of Knowledge about Schistosomiasis among Paddy Rice Farmers in Doho and Kibimba, Eastern Uganda. International Journal of Tropical Disease \& Health, 4, 12, 12091217.

Gashaw, F., Erko, B., Teklehaymanot, T., \& Habtesellasie, R. (2008). Assessment of the potential of competitor snails and African catfish Clarias gariepinus as biocontrol agents against snail hosts transmitting schistosomiasis. Transactions of the Royal Society of Tropical Medicine and Hygiene, 102, 8, 774-779.

Gouvras, A. N., Allan, F., Rabone, M., Emery, A., Pennance, T., Webster, B., Rollinson, D. \& Rollinson, D. (2017). Longitudinal survey on the distribution of Biomphalaria sudanica and B. choanomophala in Mwanza region, on the shores of Lake Victoria, Tanzania: Implications for schistosomiasis transmission and control. Parasites and Vectors, 10, 1.

Gryseels, B. (2012). Schistosomiasis. Infectious Disease Clinics of North America, 26, 2, 383-97.

Hammam, H. M., Zarzour, A. H., Moftah, F. M., Abdel-Aty, M. A., Hany, A. H., ElKady, A. Y., Nasr, A. M., \& Hussein, M. H. (2000). The epidemiology of schistosomiasis in Egypt: Qena governorate. The American Journal of Tropical Medicine and Hygiene, 62, 2, 80-7.

Habib, M. R., Lv, S., Rollinson, D., \& Zhou, X. N. (2021). Invasion and Dispersal of Biomphalaria Species: Increased Vigilance Needed to Prevent the Introduction and Spread of Schistosomiasis. Frontiers in Medicine, 8.

Imran, E. (2014). Prevalence and Intensity of Schistosomiasis in Adjacent Human Communities along the River Kochi, West Nile Region of Uganda. International Journal of Tropical Disease \& Health, 4, 6, 729-739.

Jorgensen, A., Kristensen, T. K., \& Stothard, J. R. (2007). Phylogeny and biogeography of African Biomphalaria (Gastropoda: Planorbidae), with emphasis on endemic species of the great East African lakes. Zoological Journal Linnean Society, 151, 2, 337-349.

Kazibwe, F., Makanga, B., Rubaire-Akiiki, C., Ouma, J., Kariuki, C., Kabatereine, N., Booth, M., \& Stothard, J. (2006). Ecology of Biomphalaria 
(Gastropoda: Planorbidae) in Lake Albert, Western Uganda: snail distributions, infection with schistosomes and temporal associations with environmental dynamics. Hydrobiologia, 568, 1, 433-444.

Kisanga, F.S. (1991). Schistosomiasis and related transmission factors in the lower moshi rice irrigation scheme. Thesis: Muhimbili University of Health and Allied Sciences.

Kloos, H., Passos, L. K. J., LoVerde, P., Oliveira, R. C., \& Gazzinelli, A. (2004). Distribution and Schistosoma mansoni infection of Biomphalaria glabrata in different habitats in a rural area in the Jequitinhonha Valley, Minas Gerais, Brazil: environmental and epidemiological aspects. (Memórias do instituto Oswaldo Cruz, 99, 7, 673-681.)

Kristensen, T.K. 1987. A field guide to African freshwater snails. Second edition, Danish Bilharziasis Laboratory, 11-47.

Lodge, D., Brown, K., Klosiewski, S., Stein, R., Covich, A., Leathers, B (1987). Distribution of freshwater snails: spatial scale and the relative importance of physicochemical and biotic factors. American Malacology Bulletin 5:7384.

Lu, Lijun, Zhang, Si-Ming, Mutuku, Martin, Mkoji, Gerald, \& Loker, Eric. (2016). Relative compatibility of Schistosoma mansoni with Biomphalaria sudanica and $B$. pfeifferi from Kenya as assessed by PCR amplification of the $S$. mansoni ND5 gene in conjunction with traditional methods. Parasites \& Vectors, 9, 1, 1-13.

Lydig, Anna. (2009). Factors conditioning the distribution of fresh water pulmonates, Biomphalaria spp., Bulinus spp., and Lymnea spp., in Babati District, Tanzania. Södertörns högskola, Institutionen för livsvetenskaper.

Mandahl-Barth, G. (1957). Intermediate hosts of Schistosoma; African Biomphalaria and Bulinus. Monograph Series. World Health Organization, 57, 37, 1-131.

Manyangadze, T., Chimbari, M. J., Rubaba, O., Soko, W., \& Mukaratirwa, S. (2021). Spatial and seasonal distribution of Bulinus globosus and Biomphalaria pfeifferi in Ingwavuma, uMkhanyakude district, KwaZuluNatal, South Africa: Implications for schistosomiasis transmission at micro-geographical scale. Parasites \& Vectors, 14, 1.)

Müller-Graf, C. D., Collins, D. A., Packer, C. and Woolhouse, M. E. (1997). Schistosoma mansoni infection in a natural population of olive baboons (Papio cynocephalus anubis) in Gombe Stream National Park, Tanzania. Parasitology, 15: 621-627.

Mutuku, M. W., Mwangi, I. N., Kinuthia, J. M., Maina, G. M., Lelo, E. A., Mkoji, G. M., Lu, L., \& Ochanda, H. (2017). A Comparison of Kenyan Biomphalaria 
pfeifferi and $B$. Sudanica as Vectors for Schistosoma mansoni, including a Discussion of the Need to Better Understand the Effects of Snail Breeding Systems on Transmission. Journal of Parasitology, 103, 6, 669-676.

Ntonifor, H N, \& Ajayi, J A. (2007). Studies on the ecology and distribution of some medically important freshwater snail species in Bauchi State, Nigeria. (International Journal of Biological and Chemical Sciences; Vol 1, 121-127.) Ivyspring International Publisher.

Odero, S. O., Ogonda, L., Sang, D., Munde, E. O., Shiluli, C., \& Chweya, P. (2019). Distribution of Biomphalaria Snails in Associated Vegetations and Schistosome Infection Prevalence Along the Shores of Lake Victoria in Mbita, Kenya: A Cross-Sectional Study. The East African Health Research Journal, 3, 2, 172-177.

Ofulla, A. V., Adoka, S. O., Anyona, D. N., Abuom, P. O., Karanja, D., Vulule, J. M., Okurut, T., \& Gichuki, J. (2013). Spatial distribution and habitat characterization of schistosomiasis host snails in lake and land habitats of western Kenya. Lakes \& Reservoirs: Research \& Management, 18, 2, 197215.

Opisa, S., Odiere, M. R., Jura, W. G. Z. O., Karanja, D. M. S., \& Mwinzi, P. N. M. (2011). Malacological survey and geographical distribution of vector snails for schistosomiasis within informal settlements of Kisumu City, western Kenya. Parasites \& Vectors, 4, 1, 1-9.

Phillips, S. J., Anderson, R. P., \& Schapire, R. E. (2006). Maximum entropy modeling of species geographic distributions. Ecological Modelling, 190, 34.

Pointier, J.-P., Theron, A., \& Borel, G. (1993). Ecology of the introduced snail Melanoides tuberculata (Gastropoda: Thiaridae) in relation to Biomphalaria glabrata in the marshy forest zone of Guadeloupe, French West Indies. Journal of Molluscan Studies, 59, 4, 421.

Rabone, M., Wiethase, J. H., Allan, F., Gouvras, A. N., Pennance, T., Hamidou, A. A., Webster, B. L. \& Rollinson, D. (2019). Freshwater snails of biomedical importance in the Niger River Valley: evidence of temporal and spatial patterns in abundance, distribution and infection with Schistosoma spp. Parasites \& Vectors, 12, 1.

Rowel, C., Fred, B., Kabatereine, N. B., Betson, M., Sousa-Figueiredo, J. C., Sousa-Figueiredo, J. C., \& Stothard, J. R. (2015). Environmental epidemiology of intestinal schistosomiasis in Uganda: Population dynamics of Biomphalaria (Gastropoda: Planorbidae) in Lake Albert and Lake Victoria with observations on natural infections with digenetic trematodes. Biomedical Research International, 2015, 1-11. 
Standley, C. J., Goodacre, S. L., Wade, C. M., \& Stothard, J. (2014). The population genetic structure of Biomphalaria choanomphala in Lake Victoria, East Africa: implications for schistosomiasis transmission. Parasites \& Vectors, 7, 1, 524.

Standley, C. J., Wade, C. M., \& Stothard, J. R. (2011). A fresh insight into transmission of schistosomiasis: a misleading tale of Biomphalaria in Lake Victoria. Plos One, 6, 10.)

Stanton, M. C., Adriko, M., Arinaitwe, M., Howell, A., Davies, J., Allison, G., LaCourse, E. J., \& Stothard, J. R. (2017). Intestinal schistosomiasis in Uganda at high altitude (>1400 m): malacological and epidemiological surveys on Mount Elgon and in Fort Portal crater lakes reveal extra preventive chemotherapy needs. Infectious Diseases of Poverty, 6, 1.)

Sturrock, R. F. (1965). The development of irrigation and its influence on the transmission of bilharziasis in Tanganyika. Bulletin of the World Health Organisation, 32, 225-236.

Thomas, J. D. (1987). An Evaluation of the Interactions Between Freshwater Pulmonate Snail Hosts of Human Schistosomes and Macrophytes. Philosophical Transactions of the Royal Society of London. Series B, Biological Sciences, 315, 1170, 75-125.

Utzinger, J., \& Tanner, M. (2000). Microhabitat preferences of Biomphalaria pfeifferi and Lymnaea natalensis in a natural and a man-made habitat in southeastern Tanzania. Memorias Do Instituto Oswaldo Cruz, 95, 3.)

Yang, Y., Cheng, W., Wu, X., Huang, S., Deng, Z., Zeng, X., Yuan, D., \& Secor, W. E. (2018). Prediction of the potential global distribution for Biomphalaria straminea, an intermediate host for Schistosoma mansoni. Plos Neglected Tropical Diseases, 12, 5.

Zeng, X., Yiu, W. C., Cheung, K. H., Yip, H. Y., Nong, W., He, P., Yuan, D., ... Hui, J. H. L. (2017). Distribution and current infection status of Biomphalaria straminea in Hong Kong. Parasites \& Vectors, 10, 1, 1-12.

Zhou, X.N., Wang, T.P \& Wu, X.H. (2009). Current strategy and its effect on control of schistosomiasis transmission in China. International Journal of Medical Parasitology and Epidemiology Diseases 36:266-273 